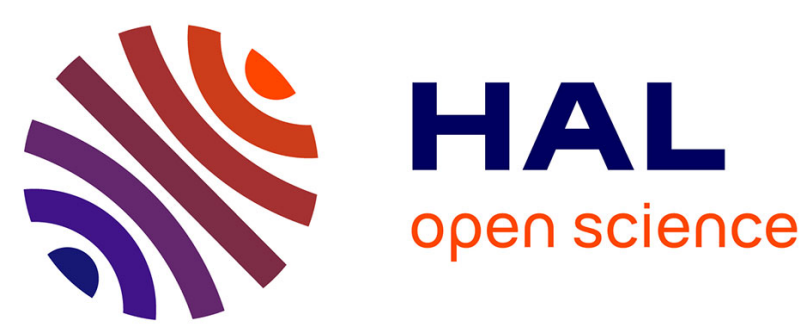

\title{
International staff contributions to their host institution: a case study in South Africa
}

Loïse Jeannin

\section{To cite this version:}

Loïse Jeannin. International staff contributions to their host institution: a case study in South Africa. International Journal for Academic Development, 2019, pp.1-14. 10.1080/1360144X.2019.1608210 . hal-02121997

\section{HAL Id: hal-02121997 \\ https://hal.science/hal-02121997}

Submitted on 20 Nov 2019

HAL is a multi-disciplinary open access archive for the deposit and dissemination of scientific research documents, whether they are published or not. The documents may come from teaching and research institutions in France or abroad, or from public or private research centers.
L'archive ouverte pluridisciplinaire HAL, est destinée au dépôt et à la diffusion de documents scientifiques de niveau recherche, publiés ou non, émanant des établissements d'enseignement et de recherche français ou étrangers, des laboratoires publics ou privés. 


\title{
International staff contributions to their host institution: a case study in South Africa
}

\author{
Loïse Jeannin
}

\section{Author version accepted for publication}

Citation : Jeannin, L. (2019). International staff contributions to their host institution : A case study in South Africa. International Journal for Academic Development, 24(3), 272- 285. https://doi.org/10.1080/1360144X.2019.1608210

\begin{abstract}
The mobility of academic staff to South Africa is expected to benefit higher education institutions through teaching-research collaboration and capacity building. However, South African institutions do not always have the adequate organisational processes to facilitate host and international staff collaboration. Drawing on individual interviews with 16 lecturers from 12 different countries, all of them teaching in one South African university, this article analyses lecturers' perceived contributions to their host university and the challenges they encountered. Recommendations revolve around the development of appropriate induction programmes and faculty forums to promote cross-cultural collaboration and the cross-fertilisation of ideas.
\end{abstract}

\section{Introduction}

One objective of the Continental Education Strategy for Africa (CESA) over the period 2016-2025 is to facilitate Pan-African mobility and academic integration through regional cooperation on teaching and research. This policy objective is consistent with the global rationale for higher education internationalisation. This internationalisation agenda aims to support the development of teaching and research quality in partnering universities, in addition to exposing students to international perspectives (Egron-Polak \& Hudson, 2014). In Africa in particular, the expected gains of internationalisation pertain to a strengthened capacity for knowledge production and opportunities for staff mobility (Egron-Polak \& Hudson, 2014). These internationalisation gains depend however on the opportunities for scholars to cross borders and contribute to their host institutions through equal collaboration with colleagues on site. The risk of unfair distribution of gains in the international brain game is a current source of worry among university leaders in Africa (Egron-Polak \& Hudson, 2014). Not only Western scholars, nor Western institutions with greater revenue streams, should benefit from international collaborations.

International academic staff members represent a valuable resource to universities competing for talent as they bring with them different sets of expertise and an inter- national network (Kim \& Locke, 2010). In this internationalised context, higher education institutions within the Southern African Development Community (SADC) are encouraged to increase international partnerships with other universities. This is promoted by organisations like the Southern African Regional Universities Association (SARUA) that approach student and academic mobility as an opportunity for capacity building of leadership, research, and teaching that has the potential of increasing attractiveness of the region (Kotecha, 2011). As academic exchanges bring about cultural diversity in higher education institution, these contexts are perceived as more productive in terms of the production of new ideas. This academic mobility will be facilitated by a credit-equivalent system - like the SADC Qualification Framework currently in implementation - and quality assurance strategies within the Southern African region.

However, academic mobility to South Africa has been described as challenging (Barkhuizen, 2002; Parr, 2012) as international lecturers are confronted with a highly racialized context that values the contributions of black South African and sees foreigners 
as a potential threat to indigenous African cultures. Peberdy and Crush (1998) identified an identitarian movement within South African society as result of the apartheid regime.

This is exacerbated by debates on the decolonisation and the Africanisation of the curriculum in South African universities (Le Grange, 2016; Vorster \& Quinn, 2017). Academic mobility also takes place in the context of the transformation of South African

of universities, which sometimes takes the form of recruitment preferences that favour historically disadvantaged people in order to achieve a more balanced representation of society in terms of race, gender, and class, especially at managerial levels. This definition of transformation is characterised by Du Preez, Simmonds, and Verhoef (2016) as 'transformation through redressing equity' (p. 6). Their article engages with current discussions around the transformation of higher education in the context of the afore- mentioned decolonisation and Africanisation of knowledge, but also in the broader context of the internationalisation of universities in South Africa (Du Preez et al., 2016). Du Preez et al. (2016) recommended "greater attention be given to the internationalisation debates informing the higher education context in order to broaden the discourse on transformation and encourage the rethinking thereof" (p. 6). The current paper contributes to this rethinking process by exploring how the internationalisation of university academic staff may contribute to the transformation of university processes related to teaching and learning. As the multi-faceted notion of transformation raises questions related to universities' structures, equity, successful access, pedagogical practices, and curriculum - curriculum content that should depart from a Eurocentric focus, according to Heleta (2016) - the process of internationalisation in South Africa could contribute to a transformative movement towards social justice and appreciation of the epistemologies of the South through the development of inclusive pedagogical and research practices (Cross, Mhlanga, \& Ojo, 2009; Maringe, 2017).

Within this broader context of internationalisation, a more particular regionalisation can also favour the development of distinctive and collaborative research programmes within Southern Africa. Academic cross-cultural forums can provide enabling spaces to produce relevant research for African contexts, embracing African indigenous epistemological frameworks, and addressing African socio-economic realities (Sehoole \& de

Wit, 2014). They could mitigate the risks of overemphasising a 'Western' epistemological approach in Africa (Egron-Polak \& Hudson, 2014). Representing 25\% of the African population, the 15 member states of the SADC region share similarities, such as a wide ethnic and language diversity, a colonial past, and common constraints (limited resources, brain drain). In 2012, it included 109 public universities, 526 technical colleges, and a fast-growing pool of private institutions (Wilson-Strydom \& Fongwa, 2012). Confronted with specific challenges on the continent, Southern African researchers can work collaboratively towards developing appropriate research and policy programmes. For example, African partnerships can enable researcher-practitioners to design locally relevant research strategies as well as regionally relevant curricula in accordance with the current emphasize on indigenous frames of references in South Africa (Le Grange, 2016; Sehoole \& de Wit, 2014).

However, as each SADC country presents specific cultural and administrative contexts, 95 including distinctive educational cultures and a myriad of languages (beyond the colonial English, French, or Portuguese languages), moving from one country to another requires lecturers to learn and adjust to different teaching philosophies and practices (Williams \& Berry, 2016). Crossing borders brings about disturbing experiences that can be conceptualised in culture shock models (Dongfeng, 2012; Kim, 2008), which describe the difficulties of the integration and socialisation processes of international academic scholars in new sociocultural contexts (Kim, 2008; Volet \& Jones, 2012).

Assessing the advantages of academic staff mobility to South Africa necessitates a review of the scope of their contributions to their host institutions and the challenges they need to overcome to unleash their full potential in a new sociocultural environment. This article focuses on transnational faculty members who teach in one South African university; more precisely, it draws on data collected from 16 international lecturers and 12 different nationalities teaching in one university in Johannesburg. This case study aims to provide an in-depth illustration of the perceived contributions of international lecturers to their host institution. Two research questions were devised to guide the study: 
- How did international faculty members perceive their contribution(s) to their host institution?

- Which challenges did they encounter in this specific context?

After reviewing the current literature on academic mobility and the value of foreign lecturers' inflow from an institutional perspective, I will present the conceptual framework and the methodology before highlighting the findings and recommendations. Facilitating international lecturers' integration into and collaboration within the host university could help them contribute more extensively to their institution.

\section{Contributions of transnational lecturers to their institutions: a literature review}

Building on the current literature on academic mobility and partnerships (Fellesson \& Mählck, 2017; Ishengoma, 2016; Kot, 2016), this literature review is organised around the expected gains and challenges attached to academic staff mobility. Issues and benefits are considered from an institutional perspective.

A growing body of cross-boundary literature explores the conditions for successful teaching experiences needed for reducing mismatched expectations between foreign teachers and their host institutions (Smith, 2014; Volet \& Jones, 2012). A large share of

the literature promotes the mutual learning of faculty from diverse cultural back- grounds (Bovill, Jordan, \& Watters, 2015; Lai, Li, \& Gong, 2016; Mizzi, 2017). The various collaboration opportunities between host and international lecturers are framed by the institutional culture, structure, and processes of the host university that together delimit the scope of their interaction opportunities (Lai et al., 2016; Shagrir, 2017). Lai et al. (2016) interviewed 14 Chinese language teachers from 13 Western/international schools in Hong Kong where English was the medium of instruction. They shed light on the sense of powerlessness perceived by these minority teachers as they reported 'limited agency to influence their Western colleagues' and sometimes an absence of desire to do so (Lai et al., p. 18). In the study by Lai et al., the participants mentioned only very few opportunities to interact with their Western colleagues through cross- disciplinary forums. In addition to addressing the limited opportunities for cross-cultural collaboration, Lai et al. highlighted the importance of considering the power relationships between staff members and of finding ways to move away from a hierarchical relationship between Northern and Southern faculty members.

A lack of individual self-confidence combined with the social roles imposed on Chinese language teachers 'as cultural agents rather than pedagogical or curricular experts' explained the lack of influence of Chinese teachers on their Western colleagues(Lai et al., 2016, p. 19). Therefore, the authors warned against the risk of local teachers undermining their own position. They recommended developing opportunities for collaboration between equally positioned teachers, and encouraged Chinese instructors to develop their agency while enabling other faculty members to learn from their perspectives - a recommendation that is aligned with Frost's (2012) advocacy for the development of teachers' non-positional leadership and collaboration.

Using the case of $\mathrm{PhD}$ research collaboration between Tanzania, Mozambique, and Sweden, Fellesson and Mählck (2017) noted that research collaboration between the North and the South could be more beneficial to Northern researchers than their Southern counterparts. They explained that funding streams from the North tended to create a feeling of subordination in Southern researchers (Fellesson \& Mählck, 2017), a relationship that has been denounced as unequal (Altbach \& Knight, 2007). Hence, distorted power relationships between Northern and Southern teachers, based on unequal access to resources and historical inequalities, should be addressed by the administration of receiving universities. 
These illustrations of power dynamics in international contexts suggest that equal cross-cultural collaboration does not happen as a matter of course and should be supported by the culture, structure, and processes of host institutions (Brooks \& Brooks, 2015). Spencer-Oatey (2013) highlighted that power inequalities, a lack of openness to new thinking, and differences in the understanding of time could impede cross-cultural collaboration. However, when effectively managed, cross-cultural academic partnerships have been praised for contributing to the professional growth of all faculty members (Dunn \& Wallace, 2008; Volet \& Jones, 2012). In the literature, the positive outcomes of cross-cultural collaboration include mutual learning in relation to 170 research and teaching, selfreflection on previously taken-for-granted assumptions about cultural differences, a greater awareness of different epistemologies, and the development of lecturers' intercultural sensitivity (Kim, 2008; Montgomery \& Bourassa- Dansereau, n.d.; Volet \& Jones, 2012; Williams \& Berry, 2016). Hence, academic staff mobility can contribute to the co-construction of ideas as international lecturers bring with them increased diversity of knowledge, competencies, and ways of doing -

a promising opportunity for universities within South Africa. However, for this promise

to be fulfilled agenda requires building on the diversity of lecturers' experiences (Lai et al., 2016) and funds of knowledge (Moll, Amanti, Neff, \& Gonzalez, 1992).

\section{Conceptual framework}

The conceptual framework of this study drew on the theories of boundary crossing (Akkerman \& Bakker, 2011; Williams \& Berry, 2016) and professional learning communities (Stoll, Bolam, McMahon, Wallace, \& Thomas, 2006; Wenger, 2011). The concept of boundary crossing is used to consider the changes encountered by lecturers who move from one country to another, thereby experiencing new national and institutional cultures. Crossing geographical and sociocultural boundaries expose lecturers to different practices

and socially accepted frames of reference, which may create disturbing experiences but could also bring about identity repositioning (Kim, 2008; Williams \& Berry, 2016). In this study, the notion of culture refers to socially accepted behaviours and assumptions that influence lecturers' teaching philosophies and practices. The adjectives transnational and international 190 are used interchangeably to qualify the lecturers who have crossed borders in order to teach

in South Africa, in accordance with Kim and Locke's (2010) use of the term transnational mobility as the movement of academic staff across countries. Their research is important for investigating underexplored phenomena, including 'the nature of international academics' experiences in their host institutions and countries and the broader impact of academic mobility on styles of scholarship and intellectual traditions' (Kim \& Locke, 2010, p. 27).

The theoretical literature on professional learning communities allows envisioning multicultural teams of lecturers as an opportunity for learning through socialisation activities and the exchange of ideas, support, and best practices (Vescio, Ross, \& Adams, 2008; Wenger, 2011). The notion of the crossfertilisation of ideas was important to frame this research as it encompasses the positive outcomes of collaboration between different-but-equal individuals with a common purpose. According to the literature, institutions which promote faculty members' active involvement enable their lecturers to pool their funds of knowledge, spur mutual learning, and enhance their collective skillsets (Lai et al., 2016; Moll et al., 1992; Tam, 2015).

\section{Methodology}

This paper builds on a qualitative study of 16 international lecturers with 12 nationalities (15 male and 1 female lecturers) in one South African university. The participants primarily came to South Africa for personal, economic, or political reasons, but also out of research interests. Some of them came for their studies without planning to remain in South Africa 
but ended up staying permanently. They held permanent job positions and had been teaching in the university from a few months to 12 years in humanities and sciences departments. At the time of the interviews, however, the majority of participants had been teaching for two to four years in Johannesburg. Six of them originated from Southern African countries, namely from the Democratic Republic of Congo (DRC), Malawi and Zimbabwe. Others came from other countries in Africa (3 participants from Cameroun and Ivory Coast), five different countries in Europe (five participants), Asia

(one participant), and North America (one participant). All participants were volunteers and had been teaching in the university for at least 10 months. The 10-month selection criterion was arbitrarily chosen to include a wide range of international lecturers while ensuring they had been working in the university long enough to be able to reflect on their onsite contributions and challenges. All participants had been teaching in another country before coming to South Africa, which could have facilitated their contributions to their new teaching institution but could also explain experiences of culture shock as they would have formed specific expectations based on their past experiences.

After receiving ethical clearance from the institution, I invited international lecturers by email and obtained their consent (signed consent forms). Depending on participants' preferences, I conducted the semi-directed interviews face-to-face or online (Meho, 2006; Rubin \& Rubin, 2005). The possibility to respond by email was offered to minimize the time burden of being interviewed face-to-face (Meho, 2006). Only four participants chose the online interview method and the content of their responses was similar to the face-to-face interviews, even though they provided shorter answers.

The interview protocol was reviewed by an international scholar to improve the relevance and accuracy of the questions. The interviews (20 to 50 minutes) were transcribed and hand-coded to reveal prominent themes related to the research questions (Creswell, 2012; Lodico, Spaulding, \& Voegtle, 2010). Codes were refined and re-organised throughout the data analysis to encompass participants' rich and diverse experiences. These codes related to pedagogical practices, participants' com- petencies, and challenging experiences. Each participant was able to review the verbatim quotes from their interview used in the research output to add any clarifications they deemed necessary. This procedure helped to enhance the validity of the results presented below.

The university that forms the context of the study is a large university in South Africa accommodating students from poor and historically disadvantaged backgrounds. Even though the university was developing a strategy for the internationalisation of its academic staff and student population at the time of the study, there was no clear policy

to attract or retain international lecturers on site.

The findings presented below describe the multiple channels through which transnational lecturers thought they contributed to their host institution. These results are limited in scope as they rely on the experiences of only 16 international lecturers. However, they provide new insights into the contributions of international lecturers to their host university despite encountered challenges.

\section{Findings: the contribution of international lecturers to their South African institution}

The study elicited the participants' perceptions of their contributions to their South African institution in terms of research, teaching, and professional development. Despite individual challenges to settle in, the transnational lecturers perceived that these contributions drew on their distinctive experiences, which could inform the university development and facilitate the inclusion of multicultural students in class. Four themes were prominent to describe how lecturers enriched their faculty or the university as a whole. In the following sections, pseudonyms are used throughout to protect participants' anonymity. 


\section{Contribution 1: different experiences and pedagogical practices}

Lecturers perceived that they brought different pedagogical experiences to the university, introduced fresh perspectives to administration, and contributed to benchmarking of practices before implementation of new programmes and qualifications. Eli explained that international lecturers could bring multi-site, cross-country experiences that might be useful in times of curriculum transformation:

At that point, you want to benchmark with what is happening overseas. That is where I come in. [The university] will then benefit because it is in transition; they want to change and offer new qualifications and now they have a bunch of people who have done the same thing.

Drawing on his own experience, Hans explained that he introduced new research practices to students as it was possible in his country of origin to initiate students' research projects very early in the course of their studies, which was less common in South Africa: 'So, some students came to me to start their own project.' Participants also reported their ability to be culturally sensitive and to effectively accommodate local and international students in class, as presented in the next subsection.

\section{Contribution 2: multicultural perspectives unfolded in teaching practices}

Participants reported that their multicultural experiences were useful in accommodating students from different cultural backgrounds. Ahmed explained:

I have colleagues around the world and we work together, so it is a kind of a United Nation experience and that translates to how I accommodate everybody. I have students from Kenya, Zimbabwe, Zambia, DRC, so I am able to relate to each person on a different level, including South Africans. [It is] like a multidimensional tool in order to accommodate those students' differences.

Lecturers acknowledged they came from countries with a different racial history than South Africa. This difference in historical heritage appeared in the way they interpreted their daily interactions with colleagues and students from diverse cultural backgrounds. As international academic staff were not impacted by the apartheid regime as were their Black and White South African colleagues, they felt they did not share the same frames of reference. Therefore, participants reported that their relationships with colleagues and students from different ethnic groups could be more relaxed. Luke felt that 'there is a room for international white lecturers [in South Africa]: they can easily step aside and deal with race issues in much less emotional and with much more distance than white South Africans.' Lecturers explained that their cross-cultural exposure could help them accommodate students from various national and cultural backgrounds, but they also felt surprised by the racial frame of references commonly used in South African universities. Patrick explained:

When interacting with a White person at [the university], I cannot pick up racist overtones immediately. I can pick them if they are clearly hatred, but if they are subtle, you won't see me picking them up. I would assume these are normal human errors, while my Black colleagues,

they immediately pick up racist overtones. And because I don't pick them up, the clash is between me and my Black colleagues, because they say, 'You favour them'. I usually say, 'No I don't, I don't see any problem here. It is not racism, it is simply human error'. So, that's the main challenge I picked. Because of that, I decided in the very first years to be very quiet and that was problematic. I was quiet on controversial issues, very quiet, people debating racist issues. And I simply said, 'No, I have no comment' and people did not like it. 
This example shows that international lecturers experienced a new sociocultural environment and approached it with their distinctive frames of references. They could reflect, learn and adjust to this new environment but also bring about different practices.

\section{Contribution 3: different research interests and awareness of world issues}

The transnational lecturers highlighted their awareness of topics or contexts that go beyond South Africa. In addition to being informed about what is happening in the rest of the world, they also bring about distinctive research interests. Rudy explained he brought 'diversity in terms of research'. This result could be compared to Shagrir's (2017) findings on collaboration, where lecturers reported a preference for research collaboration (carrying out, writing, and presenting academic research) as it permits the cross-fertilisation of ideas.

Hans explained, 'I am not only focused on South Africa. I have close collaboration with many countries.' Michael argued that he brought a different 'worldview, fresh perspective'. This comparative perspective enabled lecturers to reflect on the South African specificities, encouraging South African students to be proud of their country.

For example, Luke explained:

There is a lack of knowledge about the uniqueness of SA for [his discipline]. Indeed, the [disciplinary] inventory and resources of this country are unique in the world, and students have no conscience about it. They are not proud of their country and one challenge is to make them realise the chance they have to study [his discipline] in SA.

Finally, lecturers highlighted their language competences in a South African context with 11 official languages.

\section{Contribution 4: language competences}

The international respondents finally mentioned their language competences as a benefit for their institution and colleagues. Ahmed, from an African francophone country, illustrated his contribution. 'For example, if we go to Madagascar or Democratic Republic of Congo, most of the colleagues will be lost (...) and so having an international colleague like me who is able to navigate those worlds has been useful.' Participants highlighted that the diversity of their profiles contributed to the internationalisation agenda of the university. However, these contributions were only possible after lecturers overcame initial adaptation issues that are presented in the next paragraphs.

\section{Difficulties in unleashing lecturers' full potential}

Participants acknowledged that their productive participation in the faculty was not without hurdles. They stressed difficulties in comprehending the South African culture, deeply marked by postapartheid racial inequalities and a racial interpretive framework. They also experienced ambiguity with regard to their international profile. Daniel elaborated: 'My experience is that there is quite a lot of insecurity. In South Africa, there is a love and hate relationship with people from overseas.' Daniel's experience echoed the ambivalent relationship that South African society has developed with foreigners from poorer Southern African countries (Peberdy \& Crush, 1998) or from Western countries as a result of colonisation and the apartheid regime.

Some lecturers also mentioned they were surprised, and sometimes unprepared, to meet the demand for student-centred pedagogy promoted in the university, considering they were coming from countries that tended to use lecturer-centred approaches. This difference in pedagogical cultures was observed between faculty members coming from French- speaking and English-speaking countries within Africa, the former being more lecturer-centred than the latter due to their different higher education heritage. Ella explained: 
The South African approach is mainly student-driven and for [her French-speaking country of origin], it is the opposite, it is teacher-driven. Student-driven means that we tend to find out what the students want or what they will be happy with and then, we follow that. (. . ), in [her country of origin], the lecturer is the one who knows what is good for you and you must follow. So, it took me a while to actually understand that.

Being exposed to students with different learning needs and new institutional expectations with regard to educational objectives, lecturers reflected on their teaching roles and questioned their ways of doing. Eli departed from viewing higher education as an elitist enterprise as he started teaching students from disadvantaged backgrounds. He explained: 'Something shifted in me when I came to the realisation that these students were under-prepared (. . .) I started questioning the way I was presenting my subject.'

Participants' mixed experiences finally suggested that it was possible to better introduce international lecturers to the institutional and national cultures, enabling them to meet the wide learning needs of diverse students in South Africa and prepare them for the national debates around the decolonisation and the Africanisation of the curriculum. Induction programmes, faculty participative forums, and inclusive leadership might help transnational lecturers to thrive in their new environment by feeling valued for their distinctive competencies, epistemologies, and pedagogical practices, as argued in the last subsections.

\section{Discussion}

\section{Conceptual contributions of the paper}

The above results illustrate and confirm the relevance of boundary crossing theory (Akkerman \& Bakker, 2011; Williams \& Berry, 2016) in the South African context. More precisely, it highlights how lecturers felt puzzled by the culture and requirements of their host institution. Lecturers did not expect the racial interpretive framework that is pervasive 380 in the university as a consequence of the apartheid legacy. They experienced tensions and critical incidents that are typical when 'working in borderlands' (Parr, 2012). These experiences resulted in taking some step back to reconsider their lecturers' roles in a country with wide inequalities. For example, some African participants originating from French-speaking countries felt unprepared for the student-centred pedagogical approach required to accommodate students from poor economic backgrounds.

The findings also illustrate the notion of cross-fertilisation or cross-pollination of ideas in the South African context, as an international professional learning community (Stoll et al., 2006) could draw on lecturers' different experiences, pedagogical practices, research interests, and linguistic competences. Building an international academic staff community would require the university to set effective processes to move from a community of differences to a community of learning, which is the main objective of the practical recommendations below.

\section{Implications for academic developers}

This study has important implications for cross-cultural collaboration in a context of 395 increasing academic mobility. As the university under study was developing an internationalisation policy at the time, these results had the potential to be helpful for effectively activating the benefits of accommodating a growing body of international academic staff. It became clear from the results that host and international lecturers should be invited to collaborate in faculty meetings devoted to brainstorming and benchmarking different teaching ideas. Organising regular meetings around teaching and research could enable both host and international staff to collaborate and confront their different perspectives (National Comprehensive Center for Teacher Quality, 2010; Shagrir, 2017; Steinert, 2010). Staff mentoring and pairing could also help transnational lecturers receive peer 
support in order to facilitate their acculturation process (Darling- 405 Hammond, Wei, Andree, Richardson, \& Orphanos, 2009).

Aligned with the SADC Protocol on Education and Training, SARUA recommended academic collaboration within the Southern African region to support leadership skill development and education quality (Kotecha, 2011). Cross-cultural collaboration will enable research teams to address locally relevant issues, while 410 being inspired by international comparative perspectives. As Sehoole and de Wit (2014) stipulated: 'African scholars are challenged to produce knowledge that is relevant to their own development context and to explore avenues by which to disseminate this knowledge by and to students and scholars worldwide' (p. 235). African partnerships can 'produce tangible solutions to Southern African problems 415 that draw on both local as well as global systems of knowledge and are grounded in Southern African experience, norms and values' (Kotecha, 2011, p. 16). This would enable researchers to contribute to the development of Southern African societies by mixing different-but-equally-valued epistemologies. For example, drawing on the South African Ubuntu philosophy (Waghid \& Shanyanana, 2016) does not mean that other foreign epistemologies should be discarded but that a discussion between different approaches could contribute to the development of inclusive and innovative ideas. Therefore, lecturers' mobility to South Africa may continue developing and disseminating culturally and regionally relevant knowledge through inclusive forums in their host institutions.

\section{Limitations}

This case study drew on the experiences of only 16 lecturers in one South African university. Hence, other lecturers could have reported different experiences or distinctive contributions to their host institution. International lecturers who participated in the research came from 12 different countries. The study was therefore limited in scope and breadth, but nevertheless illustrated some of the contributions and adaptation issues reported in the literature and demonstrated their salience in the South African context. The findings highlighted the necessity of supporting international lecturers through appropriate induction programmes and participative forums.

\section{Conclusion}

As African leaders have identified the rest of Africa as their top priority to develop international partnerships (Egron-Polak \& Hudson, 2014), it is crucial to review the advantages of academic staff mobility in the context of the transformation and internationalisation of the South African higher education system (Du Preez et al., 2016; Maringe \& Sing, 2014). In this research, I investigated transnational lecturers' experiences in a South African university to elicit their perceived contributions to their new institution. This research study explored how international faculty members could contribute to their South African institutions in the national context of universities' transformation, students' demand for the decolonisation and Africanisation of the curriculum (Heleta, 2016; Le Grange, 2016), and society's support for socially just pedagogies (Maringe, 2017). Revolving around four themes, the 16 participants stressed their ability to bring fresh perspectives to their host institution through capitalising on their own experiences abroad, using their intercultural sensitivity to better accommodate their students, and bringing about different language competences and research interests. It showed how lecturers' cultural diversity is a potential source for the creation of ideas and should be better valued in a context of occasional distrust against non- South African citizens (Peberdy \& Crush, 1998).

As a result, the administration of the university should encourage the contributions of international lecturers through the organisation of participative forums to enhance the cross-fertilisation of ideas. The findings of this qualitative research indicate that induction sessions could benefit international faculty members by accelerating their socialisation and acculturation processes in the university, but also in better valuing their contributions in this post-apartheid context. Peer support, organised at the institutional level, could also accompany lecturers' self-reflection process while teaching in 
'borderlands'. These recommendations echo Lai et al.'s (2016) suggestions to scrutinise the institution's culture, structure, and capacity building procedures in order to facilitate host and international academic staff collaboration. They also encourage South African institutions to support international staff adaptation to their new sociocultural environment.

\section{References}

Akkerman, S. F., \& Bakker, A. (2011). Boundary crossing and boundary objects. Review of Educational Research, 81(2), 132-169. 470

Altbach, P. G., \& Knight, J. (2007). The internationalization of higher education: Motivations and realities. Journal of Studies in International Education, 11(3-4), 290-305.

Barkhuizen, G. (2002). Beginning to lecture at university: A complex web of socialisation patterns. Higher Education Research \& Development, 21(1), 93-109.

Bovill, C., Jordan, L., \& Watters, N. (2015). Transnational approaches to teaching and learning in higher education: Challenges and possible guiding principles. Teaching in Higher Education, 20(1), $12-23$.

Brooks, M. C., \& Brooks, J. S. (2015). Exploring opportunities and challenges of cross-cultural and international teaching, research, and service for higher education faculty members. In N. Erbe \& A. Normore (Eds.), Cross-cultural collaboration and leadership in modern organization (pp. 35-48). IGI Global.

Creswell, J. W. (2012). Educational research: Planning, conducting, and evaluating quantitative and qualitative research. Boston, MA: Pearson Education.

Cross, M., Mhlanga, E., \& Ojo, E. (2009). Emerging concept of internationalisation in South African higher education: Conversations on local and global exposure at the university of the witwatersrand (wits). Journal of Studies in International Education, 15(1), 75-92.

Darling-Hammond, L., Wei, R. C., Andree, A., Richardson, N., \& Orphanos, S. (2009). Professional learning in the learning profession: A status report on teacher development in the United States and abroad. National Staff Development Council. website. Retrieved from http:// learningforward.org/

Dongfeng, L. I. (2012). Culture shock and its implications for cross-cultural training and culture teaching. Cross-Cultural Communication, 8(4), 70-74.

Du Preez, P., Simmonds, S., \& Verhoef, A. H. (2016). Rethinking and researching transformation in higher education: A meta-study of South African trends. Transformation in Higher Education, 1(1). doi:10.4102/the.v1i1.2 495

Dunn, L., \& Wallace, M. (Eds.). (2008). Intercultural communities of practice. In Teaching in transnational higher education: Enhancing learning for offshore international students. New York, NY: Routledge.

Egron-Polak, E., \& Hudson, R. (2014). Internationalization of higher education: Growing expectations, fundamental values. (IAU 4th global survey). Paris: International Association of Universities.

Fellesson, M., \& Mählck, P. (2017). Untapped research capacities? Mobility and collaboration at the intersection of international development aid and global science regimes. International Journal of African Higher Education, 4(1). doi:10.6017/ijahe.v4i1.9740 
Frost, D. (2012). From professional development to system change: Teacher leadership and innovation. Professional Development in Education, 38(2), 205-227.

Heleta, S. (2016). Decolonisation of higher education: Dismantling epistemic violence and eurocentrism in South Africa. Transformation in Higher Education, 1(1), 8.

Ishengoma, J. (2016). Strengthening higher education space in Africa through North-South partnerships and links: Myths and realities from Tanzania public universities. Comparativeand International Education/Éducation Comparée Et Internationale, 45(1), 3.

Kim, T., \& Locke, W. (2010). Transnational academic mobility and the academic profession. In Higher education and Society: A research report (CHERI). London, UK. Retrieved from http:// www.open.ac.uk/cheri/documents/HigherEducationandSociety.pdf

Kim, Y. Y. (2008). Intercultural personhood: Globalization and a way of being. International Journal of Intercultural Relations, 32(4), 359-368.

Kot, F. C. (2016). The perceived benefits of international partnerships in Africa: A case study of two public universities in Tanzania and the democratic republic of Congo. Higher Education Policy, 29(1), $41-62$.

Kotecha, P., \& VOSESA. (2011). Engaging universities in the regional integration project in 520 Southern Africa (p. 35). Presented at the Southern African Conference on Volunteer Action for Development, Johannesburg, South Africa.

Lai, C., Li, Z., \& Gong, Y. (2016). Teacher agency and professional learning in cross-cultural teaching contexts: Accounts of Chinese teachers from international schools in Hong Kong. Teaching and Teacher Education, 54, 12-21.

Le Grange, L. (2016). Decolonising the university curriculum. South African Journal of Higher Education, 30(2), 1-12.

Lodico, M. G., Spaulding, D. T., \& Voegtle, K. H. (2010). Methods in educational research: From theory to practice (Vol. 28). San Francisco, CA: Jossey-Bass.

Maringe, F. (2017). Creating opportunities for a socially just pedagogy: The imperatives of transformation in post-colonial HE spaces. In R. Osman \& D. J. Hornsby (Eds.), Transforming teaching and learning in higher education: Towards a socially just pedagogy in a global context (pp. 59-78). Cham: Springer International Publishing. doi:10.1007/978-3-31946176-2_4

Maringe, F., \& Sing, N. (2014). Teaching large classes in an increasingly internationalising higher education environment: Pedagogical, quality and equity issues. Higher Education, 67(6), 761-782.

Meho, L. I. (2006). E-mail interviewing in qualitative research: A methodological discussion. Journal of the American Society for Information Science and Technology, 57(10), 1284-1295.

Mizzi, R. C. (2017). Bridging borders: Toward a pedagogy of preparedness for visiting faculty. Journal of Studies in International Education, 1-15. doi:10.1177/1028315316687011

Moll, L. C., Amanti, C., Neff, D., \& Gonzalez, N. (1992). Funds of knowledge for teaching: Using a qualitative approach to connect homes and classrooms. Theory into Practice, 31(2), 132-141. 
National Comprehensive Center for Teacher Quality. (2010). Job-embedded professional development: What it is, who is responsible, and how to get it done well. (Issue Brief). Washington, DC. Croft, A., Coggshall, J., G., Dolan, M., Powers, E., with Killion, J

Parr, G. (2012). Leading an international teaching practicum: Negotiating tensions in a site of border pedagogy. Asia-Pacific Journal of Teacher Education, 40(2), 97-109.

Peberdy, S., \& Crush, J. (1998). Rooted in racism: The origins of the aliens control act. In J. Crush (Ed.), Beyond control: Immigration and human rights in a democratic South Africa (pp. 18-36). Cape Town and Kingston: Idasa and Southern African Migration Project.

Rubin, H. J., \& Rubin, I. S. (2005). Qualitative interviewing: The art of hearing data (2nd ed. ed.). Thousand Oaks, CA: Sage.

Sehoole, C., \& de Wit, H. (2014). The regionalisation, internationalisation, and globalisation of African higher education. International Journal of African Higher Education, 1, 1. Retrieved from http://ejournals.bc.edu/ojs/index.php/ijahe/article/view/5648

Shagrir, L. (2017). Collaborating with colleagues for the sake of academic and professional development in higher education. International Journal for Academic Development, 22(4), 560 331342.

Smith, K. (2014). Exploring flying faculty teaching experiences: Motivations, challenges and opportunities. Studies in Higher Education, 39(1), 117-134.

Spencer-Oatey, H. (2013). Maximizing the benefits of international education collaborations managing interaction processes. Journal of Studies in International Education, 17(3), 244-261.

Steinert, Y. (2010). Faculty development: From workshops to communities of practice (AMEE guide no. 33). Medical Teacher, 32(5), 425-428.

Stoll, L., Bolam, R., McMahon, A., Wallace, M., \& Thomas, S. (2006). Professional learning communities: A review of the literature. Journal of Educational Change, 7(4), 221-258.

Tam, A. C. F. (2015). The role of a professional learning community in teacher change: A perspective from beliefs and practices. Teachers and Teaching, 21(1), 22-43.

Vescio, V., Ross, D., \& Adams, A. (2008). A review of research on the impact of professional learning communities on teaching practice and student learning. Teaching and Teacher Education, 24(1), 80-91.

Volet, S., \& Jones, C. (2012). Cultural transitions in higher education: Individual adaptation, transformation and engagement. In S. Karabenick \& T. Urdan (Eds.), Transitions across schools and cultures (Vol. 17, pp. 241-284). Bingley: Emerald Group Publishing Limited.

Vorster, J.-A., \& Quinn, L. (2017). The "decolonial turn": What does it mean for academic staff development? Education as Change, 21(1). doi:10.17159/1947-9417/2017/853

Waghid, Y., \& Shanyanana, R. N. (2016). Reconceptualizing ubuntu as inclusion in African higher education: Towards equalization of voice. Knowledge Cultures, 4(4), 104-120.

Wenger, E. (2011). Communities of practice: A brief introduction. Retrieved from https:// scholarsbank.uoregon.edu/xmlui/handle/1794/11736 
Williams, J., \& Berry, A. (2016). Boundary crossing and the professional learning of teacher educators in new international contexts. Studying Teacher Education, 12(2), 1-17.

Wilson-Strydom, M., \& Fongwa, S. N. (2012). A profile of higher education in Southern Africa. (No. Volume 1: A regional perspective). Johannesburg, South Africa: Southern African Regional Universities Association. 